\title{
Electrical Enhancement of Bone Osteogenesis Using a Totally Implantable DC Battery Disc 1.5V
}

\author{
Shokry $\mathbf{M}^{*}$ \\ Department of Surgery, Egypt
}

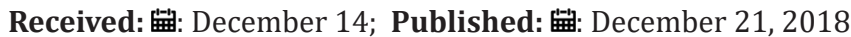

*Corresponding author: Shokry M, Department of Surgery, Faculty of Veterinary Medicine, Egypt

\section{Abstract}

A totally implantable commercial DC watch disc battery $1.5 \mathrm{~V}$ provided by 2 cathodes connected with the nearest internal fixation device while the anode was left in the adjacent tissues gave encouraging results. Healing was evaluated radiographically and histologically in experimentally osteotomized long bone dog model.

\section{Introduction}

Any mechanical stress applied on bone results in the generation of electrical potentials which exerts some level of effect on bone healing [1-3]. In subsequent studies, the significance of electrically stimulated osteogenesis was evaluated experimentally $[4,5]$ and clinically [6-8]. It has been shown that bone is formed under electronegative potentials and resorbed under electropositive potentials [9]. The objective of this study was to evaluate the effect of an implanted modified disc battery $1.5 \mathrm{~V}$ as a direct current electrostimulator (Cathodic Inductive Coupling) on fracture healing.

\section{Materials and Method}

Silver oxide disc batteries $1.5 \mathrm{~V}$ connected with resistors were used. The driving electrodes were 2 cathodes and one anode of $0.5 \mathrm{~mm}$ diameter stainless steel wire and discharging a constant direct current of $25 \mu \mathrm{A}$. The batteries were encapsulated in a silicone case and sterilized by ethylene oxide gas (Figure 1). The right femur of 2 adult anesthetized mongrel dogs was osteotomized in the middiaphysis. Each osteotomized femur was subjected to internal fixation by a compression dynamic plate and cortical screws for 8 holes. The wires of the cathodes were then connected to the nearest screws of the bone plate on either sides of the fracture osteotomy site. The wire of the anode and the battery were left under the skin. The left femurs of the same dogs were similarly treated but without batteries as a control. The current could be monitored by a sensitive galvanometer over the operation site. The animals were kept in their boxes and radiography was done at bi-weekly intervals. They were euthanized after 8 weeks for histological studies.

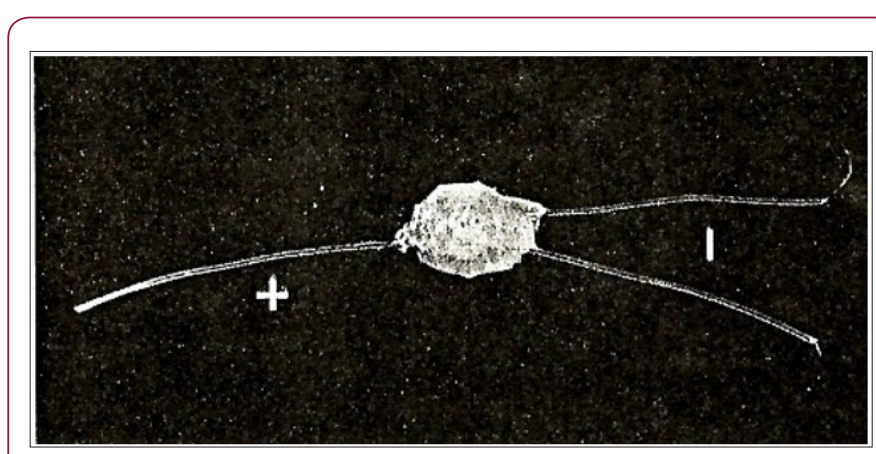

Figure 1: The encased battery with 2 insulated cathodes and one anode.

\section{Results and Discussion}

In this trial, radiological and histological results indicate the marked osteogenic response in electrically stimulated fractures with implantable disc batteries (Figures $2 \& 3$ ). In this trial, using the nearest cortical screws to the fracture line for cathodic stimulation by a such simple, low coasted method initiated an electrical field within the fracture site by inductive coupling. The negativity of the fractured bone might be augmented since the ohmic resistance of the osteosynthesis plate and screws is un remarkable. Inductive coupling was shown to enhance osteoblast differentiation and proliferation by mechanisms involving alteration of growth factors [10], gene expression [11] and trans-membrane signaling [12]. Despite variations in the methods used for electrical enhancement of bone healing, similar positive results have been reported [13- 
16]. Furthermore, electrical stimulation produces osteogenesis significantly helps union where impaired bone healing exists and can be used in a wide variety of problems: delayed union and nonunion of bones with or without chronic infection and in failed posterior spinal fusion $[17,18]$. This work opens new doors for more investigation on high number of clinical cases and the duration required to assess the effectiveness of this methods.

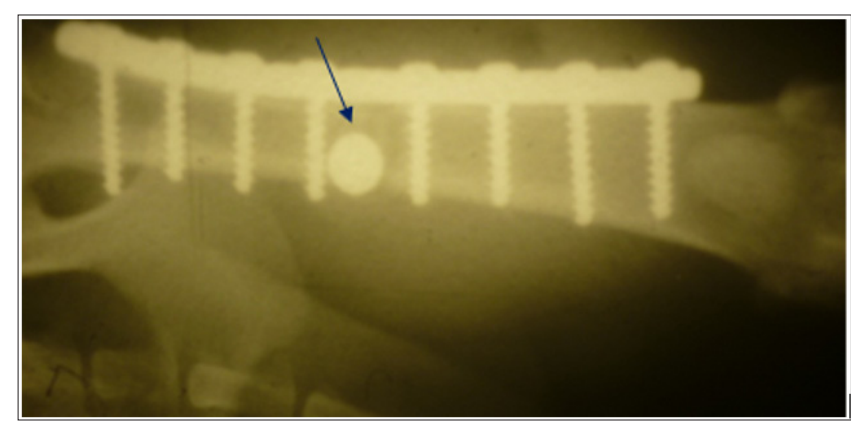

Figure 2: Radiograph of electrically stimulated fractured femur after 4 weeks with the battery (blue arrow).

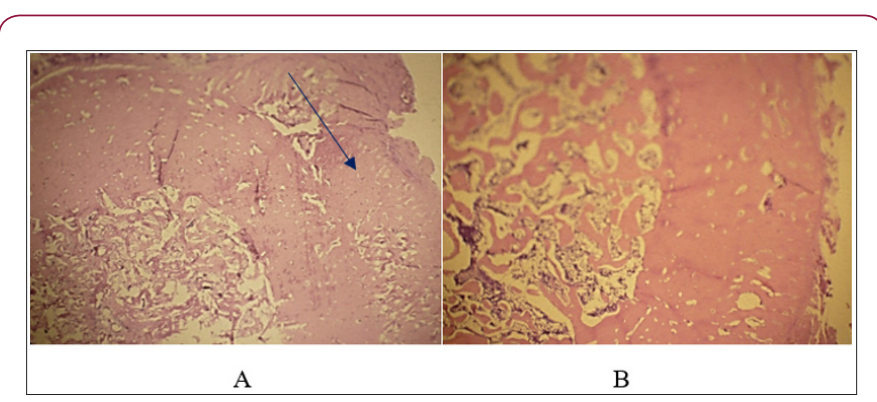

Figure 3: Periosteal and Endosteal activity.

A. Electrically stimulated ( blue arrow);

B. Control

\section{References}

1. Fakuda E, Yasuda I (1957) On the piezoelectric effect on bone. J Physiol Soc Jpn 12: 1158-1169.

2. Bassett CAL, Becker RO (1962) Generation of electric potentials by bone in response to mechanical stress. Science 137(3535): 1063-1064.

3. Becker RO, Murray D (1970) The electrical control system regulating fracture healing in amphibians. Clinical Orthop and Rel Res 73: 169198.

\section{ISSN: 2574-1241}

DOI: $10.26717 / B J S T R .2018 .12 .002261$

Shokry M. Biomed J Sci \& Tech Res

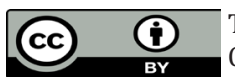

This work is licensed under Creative

Commons Attribution 4.0 License

Submission Link: https://biomedres.us/submit-manuscript.php
4. Becker R0, Spadaro JA, Marino AA (1977) Clinical experiences with low intensity direct current stimulation of bone growth. Clinical Orthop and Rel Res 124: 75-83.

5. Friedenberg ZB, Roberts PG, Didizian NH, Brighton CT (1971) Stimulation of fracture healing by direct current in the rabbit fibula. J Bone Joint Surg 53(7): 1400-1408.

6. Brighton CT, Friedenberg ZB, Mitchell EI, Booth RE (1977) Treatment of non-union with constant direct current. Clinical Orthop and Rel Res 124: 106-123.

7. Collier MA, Were KE, Defreitas CB, Lamar AA (1981) Electrostimulation of bone production in the horse. Proc of the $27^{\text {th }}$ annual convention of the amer assoc of equine practitioners, New Orleans, Louisiana.

8. Flynn DV (1981) Enhancement of osteogenesis by electrostimulation noninvasive technique. Proc of the $27^{\text {th }}$ annual convention of the amer assoc of equine practitioners, New Orleans, Louisiana.

9. Rubinacci A, Black J, Brighton CT, Friedenberg ZB (1988) Changes in bioelectric potentials on bone associated with direct current stimulation of osteogenesis. J Orthop Res 6(3): 335-345.

10. Yen Patton GP, Patton WF, Beer DM, Jacobson BS (1988) Endothelial cell response to pulsed electromagnetic fields: Stimulation of growth rate and angiogenesis in vitro. J Cell Physiol 134(1): 37-46.

11. De Mattei M, Gagliano N, Moscheni C, Dellavia C, Calastrini C, et al. (2005) Changes in polyamines, c-myc and c-fos gene expression in osteoblast like cells exposed to pulsed electromagnetic fields. Bio electromagnetics 26(3): 207-214

12. Chiabrera A, Grattarola M , Viviani R (1984) Interaction between electromagnetic fields and cells: Micro electrophoretic effect on ligands and surface receptors. Bio electromagnetics 5(2): 173-191.

13. Steinberg ME, Bosch A, Schwan A, Glazer R (1968) Electric potentials in stressed bone. Clinical Orthop and Rel Res 61: 294-299.

14. Bassett CAL, Pilla AA, Pawluk RJ (1977) A nonoperative salvage of surgically resistant pseudarthroses and non-unions by pulsing electromagnetic fields "A Preliminary Report". Clinical orthop and Rel Res (124): 128-143.

15. Dunn AW, Rush GA (1984) Electrical stimulation in treatment of delayed union and nonunion of fractures and osteotomies. South Med J 77(12): 1530-1534.

16. Kuzyk PR, Schemitsch EH (2009) The science of electrical stimulation therapy for fracture healing. Indian J Orthop 43(2): 127-131.

17. Ahl T, Andersson G, Herberts P, Kalen R (1984) Electrical treatment of non-united fractures. Acta Orthop Scan 55(6): 585-588.

18. Paterson D (1984) Treatment of nonunion with a constant current: a totally implantable system. Orthop Clin North Am 15: 47-59.

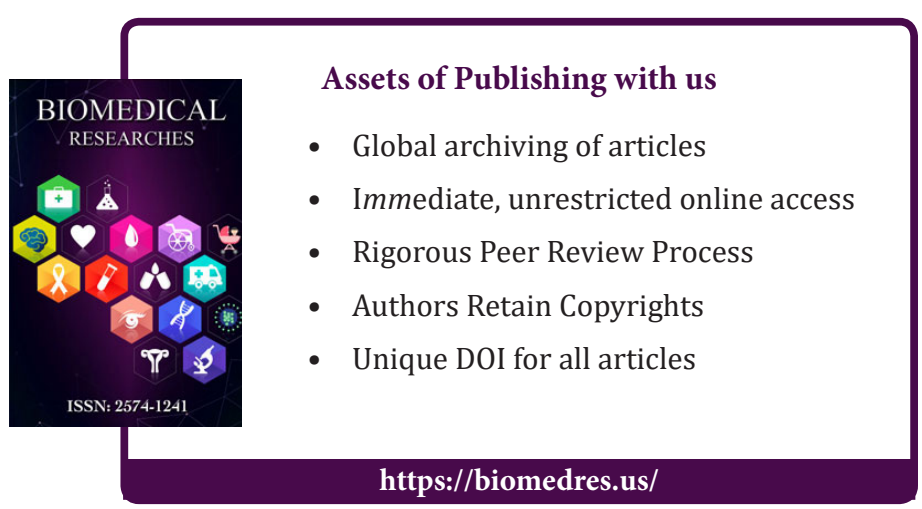

Cite this article: Shokry M. Electrical Enhancement of Bone Osteogenesis Using a Totally Implantable DC Battery Disc 1.5V. Biomed J Sci \& Tech 